\title{
Сорбция фосфатидилхолина сверхсшитыми полистиролами в динамических условиях
}

\author{
Синяева Л.А., Беланова Н.А., Карпов С.И., Селеменев В.Ф. \\ ФГБОУ ВО «Воронежский государственный университет», Воронеж
}

Поступила в редакцию 31.01.2017 г.

\begin{abstract}
Рассмотрены основные направления применения сверхсшитых полистиролов в качестве эффективных сорбентов для концентрирования и разделения фосфолипидов. Показана возможность прогнозирования выходных кривых фосфатидилхолина при его сорбции сверхсшитыми полистиролами с использованием уравнений феноменологической квазихимической и асимптотической смешанно-диффузионной моделей динамики сорбции для веществ, характеризующихся выпуклой изотермой сорбции. Показано влияние кинетических и равновесных параметров на размывание сорбционного фронта при учете внутри- и внешнедиффузионного лимитирования сорбционного процесса фосфолипидов.
\end{abstract}

Ключевые слова: фосфолипиды, фосфатидилхолин, сверхсшитый полистирол, внутридиффузионная кинетика, внешнедиффузионная кинетика, концентрирование.

\section{Sorption phosphatidylcholine supersewed polystyrene in dynamic conditions}

\author{
Siniaeva L.A., Belanova N.A., Karpov S.I., Selemenev V.F. \\ Voronezh State University, Voronezh
}

The adsorption of phosphatidylcholine by hypercrosslinked polystyrene in dynamic conditions was considered in present work. This paper discusses the possibility of effective solid phase extraction, precolumn concentration and chromatographic separation of phospholipids using the structured polymeric materials.

The sorption of phosphatidylcholine by hypercrosslinked polystyrenes (MN-102, MN-202) in the dynamic conditions is examined. The experimental and theoretical breakthrough curves calculated by means of adsorption Thomas model and asymptotic diffusional models are presented.

The mathematical models of sorption dynamics, taking into account the adsorption kinetics (Thomas model) and mixed-diffusion (the external and internal diffusion limitation) gave opportunity to determine the physicochemical parameters (equilibrium constants of adsorption, effective diffusion coefficients). The comparison of experimental and theoretical breakthrough curves led to the conclusion that the asymptotic model of sorption dynamics most adequately describes the adsorption of phosphatidylcholine by polymeric sorbents. The asymptotic diffusional model appears to be a very useful tool for studies of sorption mechanism as well as for process optimization and packed bed design of the system studied herein.

Keywords: phospholipids, phosphatidylcholine, hypercrosslinked polystyrene, pore-diffusion kinetics, external diffusion kinetics, pre-column concentration.

\section{Введение}

Определение таких неполярных биологически активных веществ (БАВ), как фосфолипиды в объектах растительного происхождения, фармацевтических 
препаратах, чаще всего осуществляют методом высокоэффективной жидкостной хроматографии (ВЭЖХ) после предварительного концентрирования веществ с помощью твердофазной экстракции (ТФЭ) $[1,2]$. В связи с этим, необходим выбор сорбентов, позволяющих осуществлять групповое или селективное выделение веществ [3]. Традиционные полимерные сорбенты со стиролдивинилбензольной матрицей, применяемые в качестве сорбентов в колоночной хроматографии фосфолипидов [4], являются гидрофобными, их взаимодействия с аналитами описываются $\pi$ - $\pi$ - взаимодействиями со значительным вкладом Ван-дер-Ваальсовых сил [5]. Один из способов улучшения удерживания аналитов на полимерных сорбентах состоит в увеличении площади поверхности материала посредством увеличения количества центров, доступных для $\pi$ - $\pi$ взаимодействий с аналитом [68]. Данная цель может быть достигнута путем использования сверхсшитых сополимеров. Известно, что степень размывания фронта сорбции в значительной степени может определяться быстротой доставки и отвода сорбата к сорбционным центрам и от них (кинетикой сорбции-десорбции). Особенности структуры гелевых полимерных материалов [9] обуславливают медленную диффузию органических веществ и, как результат, значительное размывание фронта сорбции, что не позволяет применять данный материал для эффективного выделения и разделения неполярных БАВ.

Цель настоящей работы - изучение возможности использования сверхсшитых полистиролов для эффективного сорбционного выделения, концентрирования и хроматографического разделения фосфолипидов.

\section{Эксперимент}

В работе использовали индивидуальный фосфолипид - фосфатидилхолин (L$\alpha$-phosphatidylcholine) фирмы «Sigma-Aldrich» (Германия), содержащий 95\% основного вещества, выделенный из соевых бобов. Физико-химические свойства сорбируемого фосфолипида представлены в табл. 1.

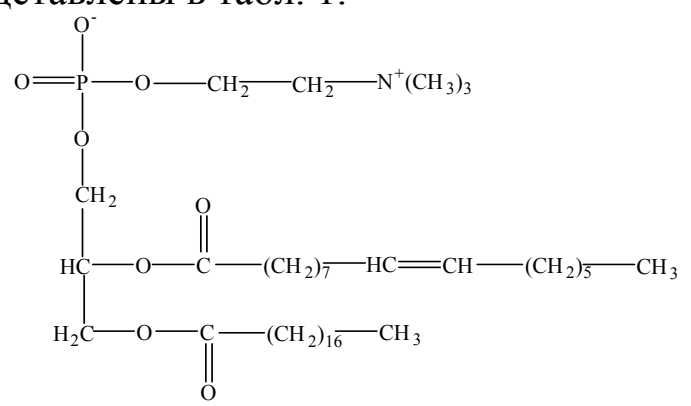

Рис. 1. Структурная формула фосфатидилхолина (биполярная форма)

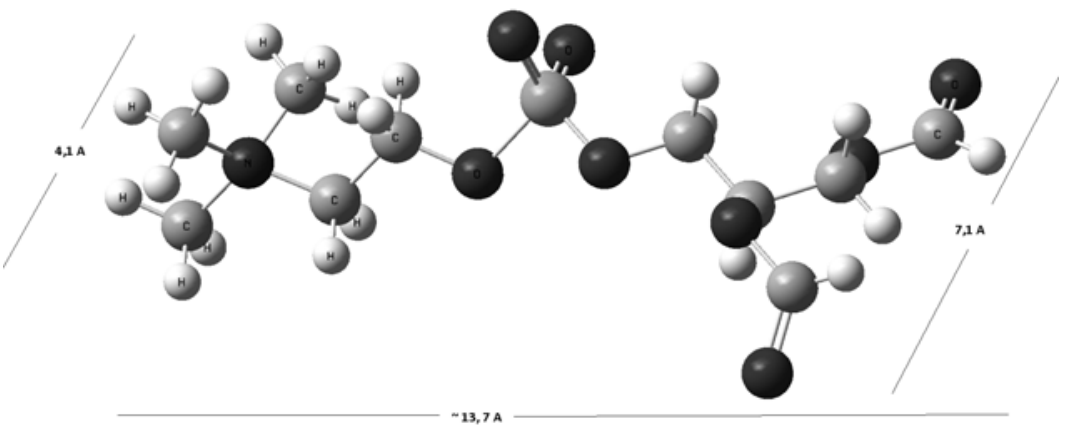

Рис. 2. Оптимизированная структура молекулы фосфатидилхолина (программа Gaussian09 в модели B3LYP/6-31G(d,p)) 
Таблица 1. Физико-химические характеристики фосфатидилхолина

\begin{tabular}{|c|c|}
\hline Название & Фосфатидилхолин \\
\hline Молярная масса, г/моль & 776.0 \\
\hline Размер молекулы, нм & $\sim 1.5$ \\
\hline
\end{tabular}

В качестве сорбентов были выбраны сверхсшитые полистирольные сорбенты серии MN («Macronet»): анионообменный сорбент MN-102 (Cl-форма), содержащий в качестве функциональных групп третичные амины и неионогенный бипористый сверхсшитый полистирол MN-202 (табл. 2).

Таблица 2. Физико-химические характеристики сверхсшитых полистиролов [6]

\begin{tabular}{|c|c|c|}
\hline Наименование показателя & MN-102 & MN-202 \\
\hline Функц. группы & Третичный амин & - \\
\hline Структура & \multicolumn{2}{|c|}{ бипористая } \\
\hline $\mathrm{S}_{\text {уд., }} \mathrm{M}^{2} /$ г (миним.) & \multicolumn{2}{|c|}{$\begin{array}{c}\text { Макропоры }-60-90 \\
\text { Микропоры }-1.5\end{array}$} \\
\hline $\mathrm{d}_{\text {пор, }}$ нм & \multicolumn{2}{|c|}{60} \\
\hline $\begin{array}{c}\text { Максимальная рабочая } \\
\text { температура, }{ }^{\circ} \mathrm{C}\end{array}$ & \multicolumn{2}{|c|}{1.4} \\
\hline $\begin{array}{c}\text { Коэффициент однородно- } \\
\text { сти (не более) }\end{array}$ & \multicolumn{2}{|c|}{} \\
\hline
\end{tabular}

Сорбция фосфатидилхолина в динамических условиях. Сорбцию фосфатидилхолина в динамических условиях изучали из индивидуальных растворов на предварительно фракционированных $\left(0.1 \div 0.25\right.$ мм), активированных при $50^{\circ} \mathrm{C}$ в течение двух часов сверхсшитых полистиролах. Динамику сорбции изучали методом выходных кривых в колонках $(d=1.3 \mathrm{~cm})$, заполненных сорбентом $(m=0.3500$ г). Объемная скорость пропускания раствора фосфолипида $\left(c=2.0 \cdot 10^{-3}\right.$ моль/дм $\left.{ }^{3}\right)$ через колонку с сорбентом с составляла $0.5 \mathrm{~cm}^{3} /$ мин. Выходные кривые фосфатидилхолина при его сорбции сверхсшитыми полистиролами строили в координатах $c / c_{0}-V / V_{0}$, проводя отбор фракций элюата объемом $2.0 \mathrm{~cm}^{3}$.

Динамическую сорбционную емкость $E^{\prime}$ (ммоль/г) рассчитывали по формуле:

$$
E^{\prime}=\sum Q
$$

где $Q=\frac{\left(c_{0}-c\right) \cdot V}{m} \cdot 1000$ - количество сорбированного вещества в каждой фракции элюата, ммоль/г; $c_{0}-$ начальная концентрация раствора, моль/дм $; c-$ равновесная концентрация раствора, моль/дм ${ }^{3} ; V$ - объём пропущенного раствора, дм ${ }^{3} ; m-$ масса навески сорбента, г, $V_{0}$ - объем сорбента в колонке, дм³

Полноту десорбции сорбата определяли во фракциях раствора по формуле (2). Десорбцию аналита осуществляли 96 \% раствором этанола, пропуская растворитель через колонку с сорбентом, насыщенным фосфолипидом. Объем фракции элюата составлял 2.0-20.0 $\mathrm{cm}^{3}$.

$$
E_{\partial e c}^{\prime}=\sum Q_{\partial e c},
$$

Количество десорбированного вещества в $i$-ой фракции элюата (ммоль/г) рассчитывали по уравнению (3):

$$
Q_{\text {деc }}=\frac{c \cdot V}{m}
$$

Количественное определение фосфатидилхолина проводили на спектрофотометре Shimadzu UV-1800 (Japan-USA) при $\lambda_{\max }=273$ нм, с толщиной поглощающего слоя $l=1.00$ см. В качестве растворителя использовали гексан (HPLC grade, Aldrich). 


\section{Обсуждение результатов}

Сорбция органических веществ в динамических условиях имеет ряд особенностей, зависящих от равновесных и кинетических параметров [11]. Сорбционно-хроматографическое разделение БАВ является весьма актуальным и может использоваться на стадиях извлечения, концентрирования, а также предшествовать определению целевых компонентов одним из физико-химических методов. В условиях фронтальной хроматографии можно оценить сорбционную емкость материала по отношению к фосфолипидам, а также добиться разделения целевых компонентов.

При сорбционном концентрировании и хроматографическом разделении органических веществ важно решение прямой задачи динамики сорбции $[12,13]$. Зная исходные концентрации веществ, характер взаимодействия между сорбентом и компонентами и другие условия, влияющие на движение и распределение в сорбирующей среде для любого момента времени. Для управления процессом сорбционно-хроматографического разделения близких по природе БАВ необходимо также и решение обратных задач: нахождение зависимостей распределения вещества между фазами, а также определение равновесных и кинетических параметров сорбции.

Оценка влияния равновесного (коэффициент распределения) и кинетического (коэффициенты диффузии) факторов на режим динамики сорбции фосфатидилхолина сверхсшитыми полистиролами позволяет демонстрировать зависимость размывания сорбционного фронта при варьировании природы сорбентов и прогнозировать изменение сорбционной способности сверхсшитых полимерных материалов. Использование сверхсшитых полистирольных материалов (MN-102, MN-202) в качестве сорбентов для извлечения фосфатидилхолина демонстрирует превосходные кинетические характеристики по сравнению с классическими полимерными сорбентами [8]. Лимитирующей стадией при сорбции фосфатидилхолина сверхсшитыми полистиролами является преимущественно внутренняя диффузия $[14,15]$. В связи с чем теоретический расчет выходных кривых проводили в рамках модели динамики сорбции с учетом смешанно-диффузионной кинетики [14, 15]. Структура сверхсшитых полистиролов (жесткая ажурная сетка) обеспечивает снижение кинетических ограничений при поглощении фосфолипида.

Описание динамики сорбции фосфатидилхолина позволяет выбирать условия сорбционного концентрирования и хроматографического разделения фосфолипидов материалами различной природы. Использование моделей динамики сорбции позволяет решать как прямую задачу динамики сорбции - нахождение функции пространственного распределения вещества в сорбционной системе к любому моменту времени, так и решение обратной задачи - определение физико-химических параметров сорбции, в том числе равновесных (констант сорбционного равновесия) и кинетических (коэффициентов диффузии $\bar{D}$ ). Одними из наиболее эффективных методов решения задач кинетики и неравновесной динамики сорбции являются: метод получения асимптотических решений для больших и малых времен [16] и феноменологическая квазихимическая адсорбционная модель Томаса [17].

Модель Томаса используют для математического выражения зависимости между концентрацией вещества в элюате и временем сорбции при заданной скорости пропускания раствора через колонку $[18,19]$.

Адсорбционная модель Томаса представляется выражением [19] (4):

Синяева и др. / Сорбционные и хроматографические процессы. 2017. Т. 17. № 2 


$$
\frac{c}{c_{0}}=\frac{1}{1+\exp \left[\frac{K_{T h}}{U}\left(q_{0} m-c_{0} V\right)\right]},
$$

где $U$ - скорость потока, $\mathrm{cm}^{3} \cdot \mathrm{c}^{-1} ; q_{0}$ - максимальная емкость сорбента, мг/г; $\mathrm{cm}^{3}$; $K_{T h}$ - константа Томаса, $\mathrm{cm}^{3} \cdot \mathrm{M \Gamma}^{-1} \cdot \mathrm{c}^{-1}$.

Для определения кинетических параметров, описывающих сорбцию в динамических условиях уравнение (4) представили в следующем виде [19]:

$$
K_{T h}\left(\frac{q_{0} m}{F}-c_{0} t\right)=\ln \left(\frac{c}{c_{0}}-1\right),
$$

Линейная форма уравнения (5) позволяет, как показано в [19], определить константу Томаса $\left(K_{T h}\right)$ и сорбционную емкость загрузки колонки по зависимости $\ln \left(c / c_{0}-1\right)$ от $t$ :

где $a=K_{T h} c_{0}, b=\frac{K_{T h} q_{0} m}{U}$

$$
Y=b-a t,
$$

На рис. 3 представлены теоретические и экспериментальные выходные кривые сорбции фосфатидилхолина из индивидуальных гексановых растворов на сверхсшитых полистиролах, рассчитанные с применением феноменологической адсорбционной модели Томаса. В линейной зависимости объемная скорость непосредственно не присутствует, однако она выражается через время сорбции [19], которое пропорционально объему раствора, отнесенному к объемной скорости потока подвижной фазы (ПФ). В рамках данной модели предусмотрено $[18,19]$, что процесс сорбции контролируется массообменными процессами между твердой и жидкой фазами. Модель Томаса описывает процесс сорбции фосфолипида при изотерме типа Ленгмюра [20].

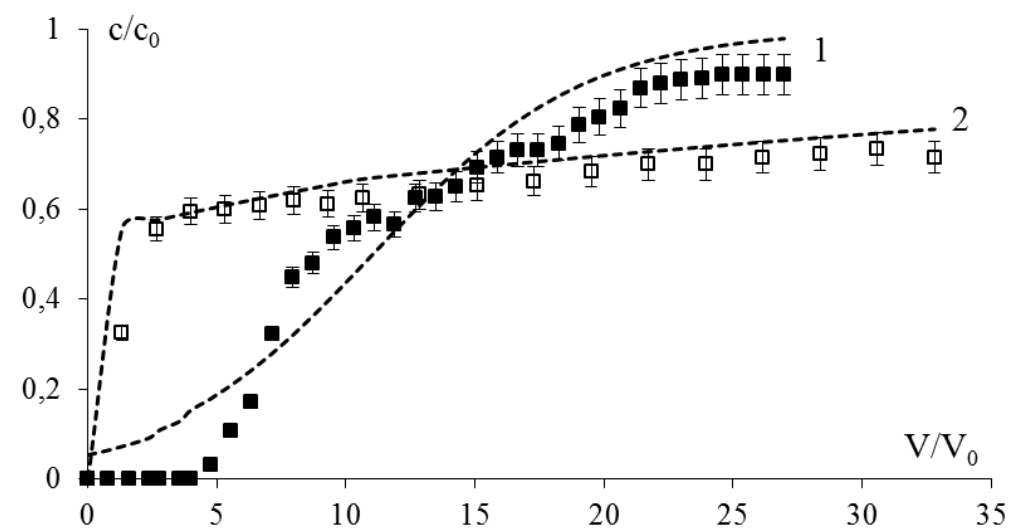

Рис. 3. Выходные кривые сорбции ФХ на: 1 - MN-102 (п); 2 - MN-202 (口) (точки - экспериментальные данные, пунктирная линия - теоретический расчет с применением феноменологической адсорбционной модели Томаса)

$$
\left(c=2 \cdot 10^{-3} \text { моль } / \text { дм }^{3}, U=0.5 \mathrm{~cm}^{3} / \text { мин, } m=0.35\right. \text { г) }
$$

Как видно из рис. 3, наличие функциональных групп сверхсшитого полистирола MN-102 (табл. 3) позволяет значительно увеличить удерживание фосфатидилхолина за счет образования дополнительных связей между молекулами фосфолипида и ионогенными группами полистирольного сорбента (рис. 3, кривая 1). При сорбции фосфатидилхолина на неионогенном бипористом MN-202, роль сорбционной емкости материала к аналиту имеет определяющее значение. Ввиду ограничений массопереноса объемных молекул фосфолипида, на выходных кривых сорбции на- 
блюдаем быстрый проскок фосфатидилхолина (рис. 3, кривая 2), следовательно, фосфатидилхолин практически не удерживается в фазе неионогенного полистирольного сорбента MN-202.

Таблица 3. Количество сорбированного фосфатидилхолина ( $E$ ', ммоль/г) сверхсшитыми полистиролами из гексановых растворов

\begin{tabular}{|c|c|}
\hline Сорбент & Фосфатидилхолин \\
\hline MN-102 & $0.95 \pm 0.5$ \\
\hline MN-202 & $0.63 \pm 0.2$ \\
\hline
\end{tabular}

Расчетные динамические выходные кривые сорбции при концентрациях фосфолипида менее 5 ммоль/дм³ имеют размытый тыл, что может быть обусловлено ограниченностью применения уравнений модели Томаса [19]. Линейные регрессии и значения коэффициентов детерминации $R^{2}$ указаны в табл. 4, где значения $R^{2}$ находятся в диапазоне от 0.865 до 0.915. Представленные расчетные кривые по адсорбционной модели Томаса подтвердили адекватность описания экспериментальных кривых только при $c / c_{0}>0.6$.

Таблица 4. Параметры сорбции фосфатидилхолина сверхсшитыми полистиролами, рассчитанные в рамках адсорбционной модели Томаса [17-19]

\begin{tabular}{|c|c|c|c|}
\hline Сверхсшитые полистиролы & $Q$, ммоль $/ \Gamma$ & $K_{T h} \cdot 10^{4}, \mathrm{~cm}^{3} \cdot \mathrm{M \Gamma}^{-1} \cdot \mathrm{c}^{-1}$ & $R^{2}$ \\
\hline $\mathrm{MN}-102$ & 0.95 & 0.8 & 0.865 \\
\hline $\mathrm{MN}-202$ & 0.63 & 1.5 & 0.915 \\
\hline
\end{tabular}

Отклонение теоретических кривых от экспериментальных при $c / c_{0}<0.6$ указывает на то, что адсорбционная модель Томаса не позволяет учитывать транспорт фосфолипида в сверхсшитых полистирольных сорбентах и адекватно описывать экспериментальные кривые в более широком интервале степени завершенности сорбционного процесса $F$. Моделирование сорбции фосфатидилхолина сверхсшитыми полистирольными сорбентами в рамках феноменологической модели Томаса не представляется возможным, так как в рамках данной модели учитывается единственный кинетический коэффициент и не рассматривается механизм сорбции. При сорбции биологически активных веществ сверхсшитыми полистиролами необходим учет многостадийности процесса, что позволяет сделать асимптотическая диффузионная модель [21]. Особенности массопереноса больших органических молекул фосфолипида предполагают возможность взаимного перехода от внешне- к внутридиффузионному лимитированию в зависимости от условий сорбции веществ.

На рис. 4 представлены расчетные и экспериментальные выходные кривые сорбции фосфатидилхолина из индивидуальных растворов на сверхсшитых полистиролах.

Сопоставление экспериментальных данных и расчетных кривых в рамках модели смешанно-диффузионной кинетики по системе уравнений (6) [21-24] (рис. 4, кривые 1-2) дает возможность адекватного описания сорбции фосфатидилхолина с использованием асимптотической диффузионной модели динамики сорбции [24].

Асимптотическое решение задачи динамики сорбции продемонстрировано в работах [21-24] при учете вклада внешне- и внутридиффузионной стадий. Расчет эффективных коэффициентов диффузии в данном подходе осуществляется по одному из уравнений [24]:

Синяева и др. / Сорбционные и хроматографические процессы. 2017. Т. 17. № 2 


$$
c_{L} / c_{0}=\left\{\begin{array}{l}
\frac{\eta}{1+\eta} \exp \left(\frac{1}{\eta}-1\right) \exp \left[\frac{12 \bar{D}}{U r_{0}^{2} \eta}\left(W-E / c_{0}\right)\right], c_{L} / c_{0} \leq \frac{\eta}{1+\eta} \\
1-\frac{1}{1+\eta} \exp (\eta-1) \exp \left[-\frac{12 \bar{D}}{U r_{0}{ }^{2} \eta}\left(W-E / c_{0}\right)\right], c_{L} / c_{0} \geq \frac{\eta}{1+\eta}
\end{array}\right.
$$

где $r_{0}-$ средний радиус зерен, см; $\bar{D}$ - эффективный коэффициент диффузии, $\mathrm{cm}^{2} / \mathrm{c}$; $\eta=4 / B i$ внутридиффузионного сопротивления к внешнедиффузионному) [24, 25].

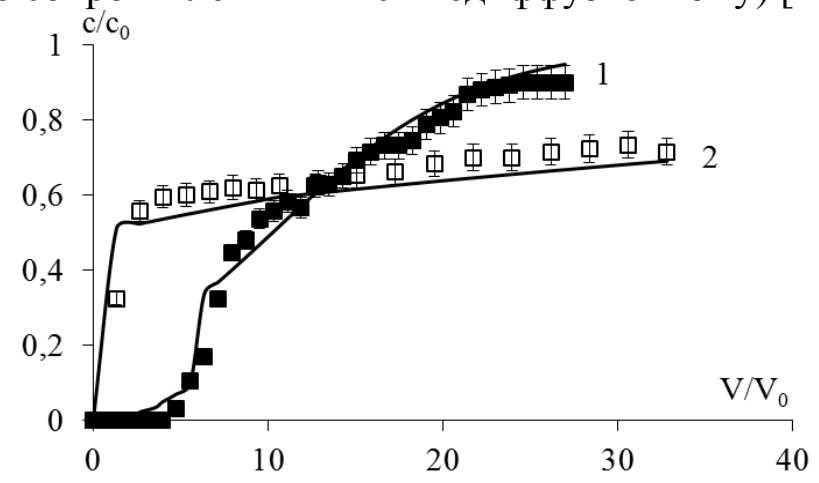

Рис. 4. Выходные кривые сорбции фосфатидилхолина на:

1 - MN-102 (匹); 2 - MN-202 (口) из гексановых растворов (линия - теоретический расчет в рамках асимптотической модели динамики, точки - экспериментальные данные) $\left(c=2 \cdot 10^{-3}\right.$ моль/дм ${ }^{3}, U=0.5 \mathrm{~cm}^{3} /$ мин, $m=0.35$ г)

При протекании сорбционно-хроматографического процесса необходим учет соотношения роли внешней и внутренней диффузии. Параметром, позволяющим определить соотношение вкладов внутренней и внешней диффузии в кинетику процесса, является критерий Био. Параметр Био определяется с использованием уравнения (7):

$$
B i=\frac{D \cdot C \cdot r_{0}}{\delta \cdot a \cdot \bar{D}}
$$

где $\delta$ - толщина диффузионного слоя, см; $c, a-$ концентрации сорбата в растворе и сорбенте, моль $/$ дм $^{3} ; D$-коэффициент диффузии сорбтива в растворе, $\mathrm{cm}^{2} \cdot \mathrm{c}^{-1}$.

Наряду со смешанно-диффузионной кинетикой сорбции фосфолипидов сверхсшитыми полистиролами необходимо учитывать избирательную сорбцию органических веществ [16]. В реальных системах сорбционный процесс в значительной мере зависит от равновесных и кинетических параметров, коэффициент диффузии будет иметь эффективный характер. При расчете по уравнению (8) следует учитывать эффективный коэффициент диффузии $(\bar{D} *)$ и модифицированный критерий Био $\left(B i^{\prime}\right)$ :

$$
B i^{\prime}=\frac{D^{*} \cdot c \cdot r_{0}}{\delta \cdot a \cdot \bar{D}^{*}}
$$

где $D^{*}$ и $\bar{D} *$ - эффективные коэффициенты внешней и внутренней диффузии сорбтива, $\mathrm{cm}^{2} \cdot \mathrm{c}^{-1}$.

Оценка величин коэффициентов диффузии, определенных из динамических выходных кривых сорбции фосфатидилхолина сверхсшитыми полистиролами позволила рассчитать теоретические кривые при условии предварительной оценки величин критерия Био (табл. 5). Значения эффективных коэффициентов диффузии $\left(D_{э \phi \phi}\right)$, рассчитанные в рамках модели смешанно-диффузионной кинетики имеют порядок $10^{-9}-10^{-8} \mathrm{~cm}^{2} \cdot \mathrm{c}^{-1}$. 
Величины коэффициентов Био (Bi) принимают значения 10-20, что свидетельствует о смешанно-диффузионном режиме сорбции фосфатидилхолина на сверхсшитых полистиролах (MN-102, MN-202) (табл. 5) с преобладающим влиянием внешней диффузии. Сопоставление экспериментальных данных и теоретических выходных кривых (рис. 4, кривые 1-2) дает возможность использования подхода, представленного в [25] к описанию динамики сорбции фосфолипидов.

Таблица 5. Равновесные и кинетические параметры сорбции фосфатидилхолина сверхсшитыми полистиролами из гексановых растворов

\begin{tabular}{|c|c|c|c|}
\hline Сорбент & $W^{l}, \mathrm{~cm}^{3}$ & $\bar{D} \cdot 10^{8}, \mathrm{~cm}^{2} \cdot \mathrm{c}^{-1}$ & $B i$ \\
\hline MN-102 & 25 & 1.4 & 20 \\
\hline MN-202 & 15 & 0.5 & 10 \\
\hline
\end{tabular}

${ }^{1}$ - исправленный объем, который мог быть очищен в случае отсутствия кинетических затруднений, определяемый, как участок, отсекаемый прямой по оси ординат из зависимости $W$ - $\varphi$.

Эффективные коэффициенты диффузии органических молекул фосфолипидов в сорбционной системе были рассчитаны при представлении выходных кривых сорбции веществ в функциональных координатах $X$ - $Y$ (рис. 5) [25].

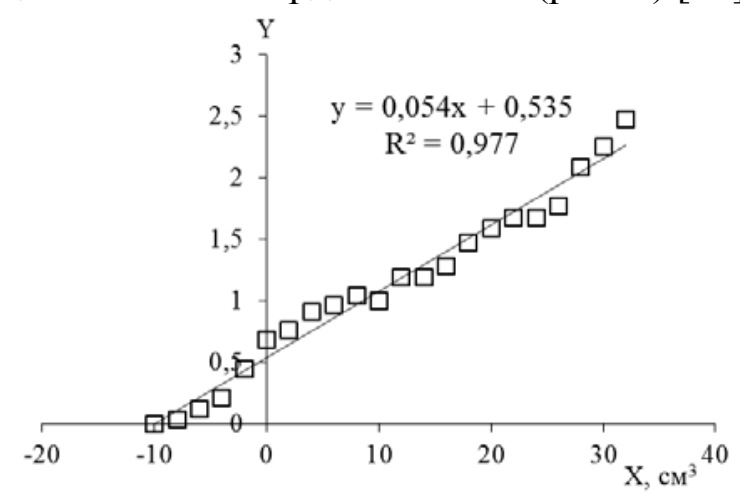

Рис. 5. Графическая интерпретация выходной кривой сорбции фосфатидилхолина на сверхсшитом полистироле MN-102 из гексанового раствора в виде функциональных координат $X$ - $Y$

Можно полагать, что в условиях массопереноса в порах при низких степенях заполнения $\left(c_{L} / c_{0} \leq \frac{\eta}{1+\eta}\right)$ преобладает внутридиффузионное лимитирование. «Проскок» вещества на выходной кривой наблюдается по мере использования сорбционной емкости материала. $c / c_{0}=\frac{\eta}{1+\eta}$ - особая точка, в которой наблюдается перегиб на выходной кривой, позволяющей учитывать смену лимитирующей стадии сорбционного процесса.

Исходя из полученных результатов показано, что с использованием феноменологической адсорбционной модели Томаса, возможно получить качественную картину влияния физико-химических параметров на вид выходных кривых аналогичную асимптотической модели динамики сорбции при смешанно-диффузионной кинетике. Теоретический расчет в рамках асимптотической модели динамики сорбции подтвердил существенную роль природы функциональных групп (их наличие в структуре сорбента) при сорбции фосфолипидов полимерными материалами. С одной стороны, наличие ионогенных групп приводит к значительному увеличению сорбционной емкости сверхсшитого полистирола MN-102 по сравнению с неионогенным аналогом MN-202, с другой - происходит усложнение механизма сорбции. В 
результате появляется необходимость учета многостадийности сорбционного процесса, что подтверждает большая адекватность описания сорбции фосфатидилхолина сверхсшитыми полистиролами в рамках асимптотической смешаннодиффузионной динамики сорбции.

Стоит отметить, что теоретические выходные кривые, полученные с использованием уравнений феноменологической адсорбционной модели Томаса симметричны, в отличие с рассмотренной ранее асимптотической моделью динамики, что связано с изменением коэффициентов диффузии в ходе процесса. Данный факт подтверждает выводы, о том, что феноменологическая адсорбционная модель Томаса в отличие от модели твердофазной диффузии не корректно описывает асимметричные выходные кривые и не позволяет учитывать смену лимитирующей стадии процесса сорбции.

\section{Заключение}

Изучена сорбция фосфатидилхолина сверхсшитыми полистиролами в динамических условиях. Выбор условий сорбционного выделения, концентрирования и хроматографического разделения близких по природе и физико-химическим свойствам биологически активных веществ, таких как фосфолипиды, осуществляется с учетом влияния вклада кинетических и равновесных параметров в сорбцию веществ, принимая во внимание взаимовлияния в системе сорбат-сорбент-элюент.

Использование феноменологической модели Томаса при моделировании сорбции фосфатидилхолина сверхсшитыми полистиролами не позволяет учитывать многостадийность сорбционного процесса и смену лимитирующей стадии. Адекватность применения асимптотической модели динамики сорбции фосфатидилхолина сверхсшитыми полистирольными сорбентами подтверждается соответствием экспериментальных и расчетных выходных кривых. Применение модели динамики сорбции с учетом смешанно-диффузионного лимитирования позволяет описать динамические кривые, а также спрогнозировать их вид при варьировании параметров, влияющих на ход сорбционно-хроматографического процесса. Решение обратной задачи динамики сорбции в рамках асимптотической модели смешаннодиффузионной кинетики позволило определять кинетические коэффициенты, а также определять вклад внешней и внутренней диффузии в массоперенос фосфолипида в сорбционной системе при использовании сверхсшитого полистирола в качестве неподвижной сорбирующей фазы.

\section{Список литературы}

1. Сафонова Е.Ф., Селеменев В.Ф., Ермошевич О.Н. и др. // Сорбиионные и хроматографические прочессы. 2001. Т. 1. № 3. С. 544-545.

2. Рудаков О.Б., Селеменев В.Ф., Железная Т.А. и др. // Сорбционные и хроматографические прочессы. 2002. Т. 2. № 2. С. 203-208.

3. Синяева Л.А., Назарова А.А., Селеменев В.Ф. // Сорбиионные и хроматографические nроиесcыl. 2013. T. 13. № 2. С. 182-187.

4. Рычкова С.А., Ланин С.Н., Шаталов И.А. и др. // Сорбиионные и хроматографические проиессы. 2014. Т. 14. Вы№3. С. 397-405.
5. Huck C.W., Bonn G.K. // Journal of Chromatography A. 2000. Vol. 885. pp. 51-72.

6. Даванков В.А., Цюрупа М.П. Сверхсшитые полистирольные сорбенты. Структура, свойства, применение. Palmarium Academic Publishing. 2012. $76 \mathrm{c}$.

7. Tsuyrupa M.P., Davankov V.A. // Reactive and Functional Polymers. 2002. Vol. 53. pp. 193-203.

8. Карцова Л.А., Бессонова Е.А., Объедкова Е.В. // Сорбиионные и хроматографические npouseccbl. 2010. T. 10. № 1 C. 5-14. 
9. Удалова Н.А., Карпов С.И., Селеменев В.Ф. и др. // Журнал физической химии. 2009. T. 83. № 6. C. 1143-1149.

10. Davankov V.A., Tsyurupa M.P. // Comprehensive Analytical Chemistry Elsevier. 2011. Vol. 56. $670 \mathrm{p}$.

11. Rudzinski W., Panczyk T. // Journal of Physical Chemistry. 2000. pp. 9149-9162.

12. Веницианов Е.В., Ковалев И.А., Цизин Г.И. // Теория и практика сорбчионных процессов. Межвузовский сб. науч. трудов. 1998. Т. 23. С. 24-40.

13. Рачинский В.В. Введение в общую теорию динамики сорбции и хроматографии. М. Наука. 1964. 135 с.

14. Синяева Л.А.дис. канд. хим. наук : 02.00.04 Воронеж. 2016. 217 с.

15. Синяева Л.А., Карпов С.И., Беланова Н.А. и др. // Журнал физической химии. 2015. T. 89. № 12. C. 1923-1930.

16. Шатаева Л.К. Карбоксильные катиониты в биологии. Ленинград. Наука. 1979. 286 c.

17. Bohart G.S., Adams E.Q. // Journal of the American Chemical Society. 1920. Vol. 8. pp. 523-544.

\section{References}

1. Safonova E.F., Selemenev V.F., Ermoshevich H.E. et al., Sorbtsionnye i khromatograficheskie protsessy, 2001, Vol. 1, No 3, pp. 544545.

2. Rudakov O.B., Selemenev V.F., Iron T.A. et al., Sorbtsionnye i khromatograficheskie protsessy, 2002, Vol. 2, No 2, pp. 203-208.

3. Sinyaeva L.A., Nazarova A.A., Selemenev V.F., Sorbtsionnye i khromatograficheskie protsessy, 2013, Vol. 13, No 2, pp. 182-187.

4. Rychkova S.A., Lanin S.N., Shatalov I.A. et al., Sorbtsionnye $i$ khromatograficheskie protsessy, 2014, Vol. 14, No 3, pp. 397-405.

5. Huck C.W., Bonn G.K., Journal of Chromatography A., 2000, Vol. 885, pp. 51-72.

6. Davankov V.A., Tsuyrupa M.P. Supersewed polystyrene sorbents. Structure, properties, applications. Palmarium Academic Publishing, 2012, $76 \mathrm{p}$.

7. Tsuyrupa M.P., Davankov V.A., Reactive and Functional Polymers, 2002, Vol. 53, pp. 193-203.
18. Alberti G., Amendola V., Pesavento M. // Coordination Chemistry Reviews. 2012. Vol. 256. pp. 28-45.

19. Chu K.H. // Journal of Hazardous Materials. 2010. Vol. 177, pp. 1006-1012.

20. Langmuir I. // Journal of the American Chemical Society. 1917. № 39(9). pp. 18481906.

21. Кузьминых В.А., Мелешко В.П. // Журнал физической химии. 1980. Т. 54. Вып. 3. С. 973-978.

22. Кузьминых В.А., Мелешко В.П., Голицын В.Ю. // Журнал физической химии. 1980. Т. 54. Вып. 7. С. 1802-1806.

23. Кузьминых В.А., Чикин Г.А., Селеменев В.Ф. // Труды VIII региональной конференции «Проблемы химии и химической технологии». - Воронеж, 2000. С. 123-128.

24. Кузьминых В.А., Чикин Г.А., Голицын В.Ю. // Журнал физической химии. 1984. Т. 58. Вып. 11. С. 2778-2782.

25. Карпов С.И., Беланова Н.А., Корабельникова Е.О. и др. // Журнал физической химии. 2015. Т. 89. № 5. С. 855-860.

8. Kartsova L.A., Bessonova E.A., Obedkova E.V., Sorbtsionnye $i$ khromatograficheskie protsessy, 2010, Vol. 10, No 1, pp. 5-14.

9. Udalova N.A., Karpov S.I., Selemenev V.F. et al., J. of Physical Chemistry A., 2009, Vol. 83, No 6, pp. 1006-1011.

10. Davankov V.A., Tsyurupa M.P., Comprehensive Analytical Chemistry Elsevier, 2011, Vol. 56, 670 p.

11. Rudzinski W., Panczyk T., J. of Physical Chemistry, 2000, pp. 9149-9162.

12. Venitsianov E.V., Kovalev I.A., Tsizin G.I., Theory and practice of sorption processes. Intercollegiate Sat scientific. Works, 1998, Vol. 23, pp. 24-40.

13. Raczynski V.V. Introduction to the general theory of sorption dynamics and chromatography. Moscow, Nauka Publ., 1964, 135 p.

14. Sinyaeva L.A. Dis.. cand. Chem. Sciences: 02.00.04, Voronezh, 2016, 217 pp.

15. Sinyaeva L.A., Karpov S.I., Belanova N.A. et al., J. of Physical Chemistry A., 2015, Vol. 89, No 12, pp. 2278-2284. 
16. Shataeva L.K. The carboxyl cation in biology. Leningrad, Nauka Publ., 1979, 286 p.

17. Bohart G.S., Adams E.Q., J. of the American Chemical Society. 1920, Vol. 8, pp. 523544.

18. Alberti G., Amendola V., Pesavento M. et al., Coordination Chemistry Rewiews. 2012. Vol. 256, pp. 28-45.

19. Chu K.H.,/ J. of Hazardous Materials. 2010, Vol. 177, pp. 1006-1012.

20. Langmuir I. , J. of the American Chemical Society. 1917, No 39(9), pp. 1848-1906.

21. Kuz'minykh V.A., Myaleshka V.P., J. of Physical Chemistry, 1980, Vol. 54, No 3, pp. 973-978.

Синяева Лилия Александровна - ведущий инженер кафедры аналитической химии Воронежского государственного университета, Воронеж, тел.(473)220-89-32

Беланова Наталья Анатольевна - к.х.н., ассистент кафедры аналитической химии Воронежского государственного университета, Воронеж, тел.(473)220-89-32

Карпов Сергей Иванович - к.х.н., доцент кафедры аналитической химии Воронежского государственного университета, Воронеж, ел.(473)220-89-32

Селеменев Владимир Федорович - д.Х.Н., профессор, зав. каф. аналитической химии Воронежского государственного университета, Воронеж, тел.(473)220-89-32
22. Kuz'minykh V.A., Myaleshka V.P., Golitsyn V.Y., J. of Physical Chemistry, 1980, Vol. 54, No 7, pp. 1802-1806.

23. Kuz'minykh V.A., Chikin G.A., Selemenev V.F., Proceedings of the VIII Regional Conference "Problems of Chemistry and Chemical Technology." Voronezh, 2000, pp. 123-128.

24. .Kuz'minykh V.A., Chikin G.A., Golitsyn V.Y., J. of Physical Chemistry, 1984, Vol. 58, No 11, pp. 2778-2782.

25. Karpov S.I., Belanova N.A., Korabel'nikova E.O. et al., J. of Physical Chemistry, 2015, Vol. 89, No 5, pp. 880-884.

Siniaeva Liliia A. - the senior engineer, department of Analytical Chemistry, Voronezh State University, e-mail: liliya.sinyaevavsu@mail.ru

Belanova Natalia A. - the assistant of the department of Analytical Chemistry, Voronezh State University, e-mail: belanovana@mail.ru

Karpov Sergey I. - the senior lecturer of department of Analytical Chemistry, Voronezh State University, e-mail: karsiv@pochta.ru

Selemenev Vladimir F. - the professor, head of the department of Analytical Chemistry, Voronezh State University, e-mail: common@chem.vsu.ru 